\title{
Titanium plates for primary closure of complete sternal cleft in an adult: Five-year follow-up
}

Khaled E. Al-Ebrahim, FRCSC, and Husain H. Jabbad, FRCSC

A 39-year-old woman was seen for obvious cardiac and aortic pulsations as a result of complete sternal cleft. Computed tomographic scan showed the cleft to be $6 \mathrm{~cm}$ wide and complete (Figure 1). The patient underwent primary closure of the cleft with titanium plates (Figure 2). A single starshaped titanium plate and 2 longitudinal titanium plates was used for the repair. The plates were secured with screws to the adjacent ribs. Five years later, follow-up has proved the efficacy of this closure in providing both physical protection and patient satisfaction. A recent follow-up computed tomographic scan is shown in Figure 3. This report, the first in the literature of the repair of such a defect in an adult of this age, shows that primary closure is possible without the need for complex sternal reconstruction.
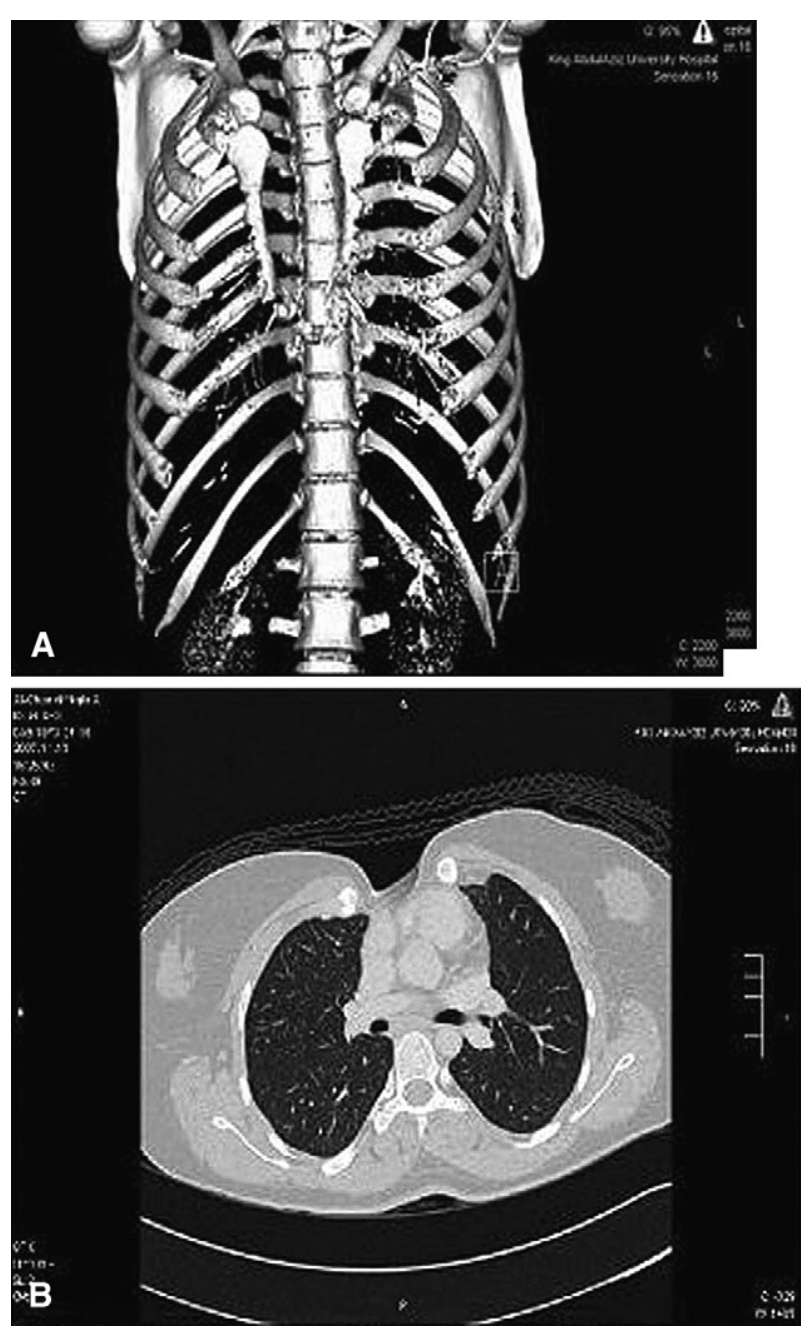

FIGURE 1. A, Preoperative 3-dimensional reconstructed computed tomographic scan. B, Cross-section of computed tomographic scan showing the defect.

\footnotetext{
From the Department of Cardiothoracic Surgery, King Abdulaziz University Hospital, Jeddah, Saudi Arabia.

Disclosures: Authors have nothing to disclose with regard to commercial support.

Received for publication Jan 9, 2012; accepted for publication Jan 16, 2012; available ahead of print Feb 13, 2012.

Address for reprints: Khaled E. Al-Ebrahim, FRCSC, Department of Cardiothoracic Surgery, King AbdulAziz University Hospital, PO Box 80215, Jeddah 21589 Saudi Arabia (E-mail: dr.k-e@ hotmail.com).

J Thorac Cardiovasc Surg 2012;143:1219-20

$0022-5223 / \$ 36.00$

Copyright (c) 2012 by The American Association for Thoracic Surgery

doi:10.1016/j.jtcvs.2012.01.038
} 


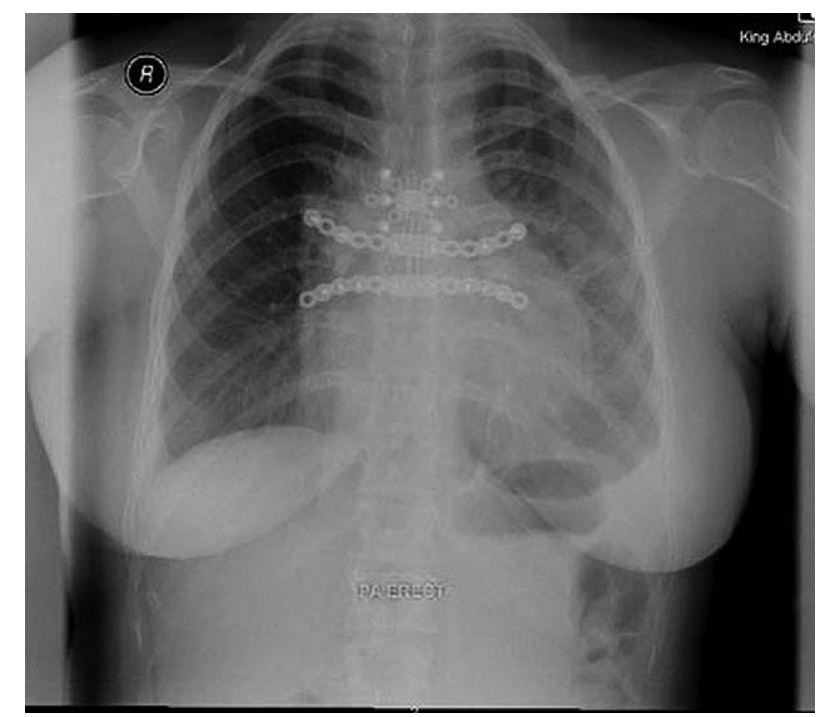

FIGURE 2. Postoperative chest radiograph showing the titanium plates.

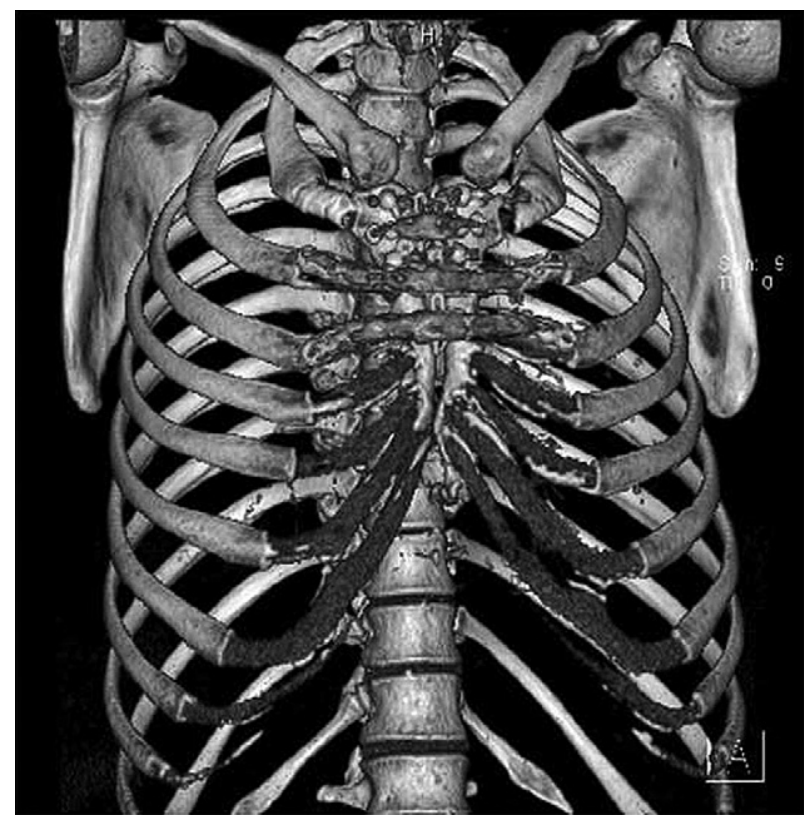

FIGURE 3. Postoperative 3-dimensional reconstructed computed tomographic scan. 